\title{
PRODUÇÃO E AVALIAÇÃO DE BRIQUETES DE FINOS DE CARVÃO VEGETAL COMPACTADOS COM RESÍDUO CELULÓSICO PROVENIENTE DA INDÚSTRIA DE PAPEL E CELULOSE ${ }^{1}$
}

\author{
Mariana Provedel Martins ${ }^{2 *}$, Elizabeth Lemos Benício ${ }^{3}$, Ananias Francisco Dias Júnior ${ }^{4}$, Rodrigo Braga de \\ Almeida $^{5}$, Alexandre Monteiro de Carvalho ${ }^{3}$ e Fábio Minoru Yamaji ${ }^{2}$
}

\footnotetext{
${ }^{1}$ Recebido em 03.02.2014 aceito para publicação em 18.11.2015.

${ }^{2}$ Universidade Federal de São Carlos, Departamento de Ciências Florestais, Sorocaba, SP - Brasil. E-mail: <mareprovedel@hotmail.com> e $<$ fmyamaji@hotmail.com $>$.

${ }^{3}$ Universidade Federal Rural do RJ, Departamento de Ciências Florestais, Seropédica, RJ - Brasil. E-mail:<beth.benicio@yahoo.com.br> e<amcarvalho@ufrrj.br>.

${ }^{4}$ Escola Superior de Agricultura "Luiz de Queiroz" da Universidade de São Paulo - ESALQ/USP, Programa de Pós-Graduação em mestrado de Recursos Florestais. E-mail: <ananiasjr@ufrrj.br>.

${ }^{5}$ Universidade Federal Rural do RJ, Graduado em Engenharia Florestal, Seropédica, RJ - Brasil. E-mail: <rokaed_4@hotmail.com>.

*Autor para correspondência.
}

RESUMO - Este trabalho teve por objetivo avaliar briquetes produzidos a partir de finos de carvão vegetal compactados com resíduo celulósico gerado na decantação dos efluentes da indústria de papel e celulose. Foram realizados os seguintes tratamentos: briquetes produzidos com fino de carvão vegetal e resíduo celulósico nas proporções de $25 \%\left(\mathrm{~T}_{1}\right), 30 \%\left(\mathrm{~T}_{2}\right), 35 \%\left(\mathrm{~T}_{3}\right), 40 \%\left(\mathrm{~T}_{4}\right)$ e $45 \%\left(\mathrm{~T}_{5}\right)$ e briquetes produzidos com finos de carvão vegetal com $10 \%$ de amido e resíduo celulósico nas proporções de $0 \%\left(\mathrm{~T}_{6}\right), 5 \%\left(\mathrm{~T}_{7}\right), 10 \%\left(\mathrm{~T}_{8}\right), 15 \%\left(\mathrm{~T}_{9}\right), 20 \%\left(\mathrm{~T}_{10}\right)$ e $25 \%\left(\mathrm{~T}_{11}\right)$. A caracterização dos briquetes foi realizada por meio de ensaios de análise química imediata, determinação do poder calorífico superior, densidade aparente e avaliação da resistência mecânica após a secagem dos briquetes em estufa ou ao ar livre. Observou-se que os briquetes com resíduo celulósico e amido em sua composição apresentaram maior densidade e resistência mecânica à compressão, concluindo-se, assim, que a presença do amido favoreceu a compactação e estabilidade dos briquetes. Observou-se, também, que o processo de secagem em estufa prejudicou a qualidade dos briquetes, de modo que a secagem ao ar livre forneceu briquetes mais resistentes e estáveis.

Palavras-chave: Bioenergia; Biomassa; Aproveitamento de resíduos.

\section{PRODUCTION AND EVALUATION OF CHARCOAL FINES BRIQUETTES COMPRESSED WITH CELLULOSIC WASTE FROM PAPER AND PULP INDUSTRY}

\begin{abstract}
This study aimed to evaluate briquettes produced from charcoal fines compressed with cellulosic residue generated in settling of the effluents from pulp and paper industry. The following treatments were performed: briquettes produced with charcoal fines and cellulosic residue in a ratio of $25 \%\left(T_{1}\right), 30 \%\left(T_{2}\right)$, $35 \%\left(T_{3}\right), 40 \%\left(T_{4}\right), 45 \%\left(T_{5}\right)$ and briquettes produced with charcoal fines, $10 \%$ starch and cellulosic residue in a ratio of $0 \%\left(T_{\sigma}\right), 5 \%\left(T_{7}\right), 10 \%\left(T_{8}\right), 15 \%\left(T_{q}\right), 20 \%\left(T_{10}\right)$ and $25 \%\left(T_{11}\right)$. Briquettes characterization was performed using immediate chemical analyses, determination of gross calorific value, apparent density and evaluation of their mechanical resistance after drying the briquettes in a kiln or outdoors. It was observed that briquettes with cellulosic residue and starch in their composition showed higher density and mechanical resistance to compression, thus concluding that the presence of starch favors briquettes compression and stability. It was also observed that the drying process in a kiln impaired the quality of the briquettes, so that the drying process outdoors resulted in more stable and resistant briquettes.
\end{abstract}

Keywords: Bioenergy; Biomass; Residues recovery. 


\section{INTRODUÇÃO}

O carvão vegetal, também conhecido como carvão de biomassa, é produzido a partir da madeira pelos processos de carbonização ou pirólise (SAMI et al., 2001) e representa uma forma de energia renovável de expressiva importância no Brasil, uma vez que o país é o maior produtor mundial desse insumo, com aproximadamente um quarto da produção mundial, seguido de países como Etiópia, Nigéria e Índia (BAILIS et al., 2013).

Ao contrário do que aconteceu nos países desenvolvidos, o uso industrial do carvão vegetal ainda é largamente praticado, sendo quase a totalidade da produção brasileira destinada ao setor siderúrgico para a produção de ferro-gusa, aço e ferro-ligas. O setor residencial consome cerca de $9 \%$, seguido pelo setor comercial com $1,5 \%$, sendo representado por pizzarias, padarias e churrascarias (MACHADO et al., 2010; BAILIS et al., 2013).

Um problema associado à característica física do carvão vegetal é a sua friabilidade, ou seja, sua capacidade de se fragmentar em pequenos pedaços. Durante a produção, o transporte e o manuseio do carvão produzem em torno de $25 \%$ de finos, o que dificulta ou, até mesmo, inviabiliza a sua utilização (ROUSSET et al., 2011). Nesse contexto, fica clara a necessidade da recuperação e reutilização desses finos, uma vez que eles possuem grande potencial energético. A briquetagem, por exemplo, permite a reutilização dos finos na forma de biocombustível sólido para a geração de energia térmica ou elétrica, transformando-os em um produto com maior valor agregado (DERMIBAS, 1999).

O processo de briquetagem consiste na aplicação de pressão a uma massa de partículas, com ou sem a adição de ligante e temperatura. A briquetagem do carvão vegetal na forma de finos se faz a partir da sua compactação com o auxílio de um aglutinante, a fim de proporcionar a coesão nos briquetes (FONTES et al., 1989). Em princípio, qualquer material pode ser utilizado como um aglutinante, e a escolha do material ligante deve ser realizada de modo que ele não prejudique as características energéticas dos briquetes (diminuindo o seu poder calorífico ou aumentando seu teor de voláteis e cinzas) e não gere gastos que inviabilizem economicamente a produção dos briquetes (FONTES et al., 1984; ONAJI et al., 1993; PEREIRA et al., 2009).

Revista Árvore, Viçosa-MG, v.40, n.1, p.173-180, 2016
O aglutinante mais utilizado na produção de biocombustível sólido é o amido de milho industrial não refinado (ROUSSET et al., 2011). Contudo, outros ligantes como resina sintética, breu, lignina, cola de tanino, melaço, alcatrão vegetal e bagaço de cana-deaçúcar vêm sendo estudados (FONTES et al., 1984; PEREIRA et al., 2009). O resíduo celulósico empregado neste trabalho foi proveniente da indústria de produção de papel, sendo ele formado a partir das fibras de resíduos de madeira e da água retiradas por meio de drenagem e vácuo durante a secagem do papel. Esse resíduo já foi bastante utilizado como fertilizante orgânico natural para a produção florestal (ANDRADE et al., 2003; HARRISON et al., 2003; RODRIGUES et al., 2005) e como matéria-prima em outras unidades industriais, como nas olarias (para a fabricação de tijolos e telhas), mas, devido aos entraves burocráticos da legislação ambiental, as parcerias para o reaproveitamento desse resíduo são praticamente inexistentes.

Nesse contexto, este trabalho teve como objetivo testar a produção de briquetes de finos de carvão vegetal utilizando, adicionalmente em sua composição, o material residual da indústria de papel e celulose e/ou, amido de milho como aglutinante, com o intuito de avaliar a viabilidade do reaproveitamento desse resíduo em substituição parcial ou total ao amido de milho industrial.

\section{MATERIAL E MÉTODOS}

\subsection{Material Utilizado}

Os finos de carvão vegetal utilizados na confecção dos briquetes foram provenientes de moinha de carvão vegetal de Eucalyptus spp. fornecidos pela Empresa Eco-Briquetes, situada no Município de Volta Redonda, no Estado do Rio de Janeiro. Os finos coletados foram passados em peneira classificatória com malha de 3,0 $\mathrm{mm}$ para a homogeneização do material. O resíduo celulósico foi obtido na indústria de papéis SchweitzerMauduit do Brasil, situada no Município de Barra do Piraí, no Estado do Rio de Janeiro.

\subsection{Confecção dos Briquetes}

Na Tabela 1 são apresentadas as composições dos briquetes dos diferentes tratamentos que foram realizados.

$\mathrm{O}$ amido de milho adicionado aos tratamentos $\mathrm{T}_{6}$ $\mathrm{T}_{11}$ foi preparado utilizando $20 \mathrm{~g}$ de amido dissolvido 
Tabela 1 - Composição dos briquetes analisados. Table 1 -Composition of the analyzed briquettes.

\begin{tabular}{cccc}
\hline Tratamentos & & Composição do Briquete & \\
\cline { 2 - 4 } & Finos de carvão vegetal & Resíduo celulósico & Amido \\
\hline 01 & 75 & 25 & - \\
02 & 70 & 30 & - \\
03 & 65 & 35 & - \\
04 & 60 & 40 & - \\
05 & 55 & 45 & - \\
06 & 90 & 0 & 10 \\
07 & 85 & 5 & 10 \\
08 & 80 & 10 & 10 \\
09 & 75 & 15 & 10 \\
10 & 70 & 20 & 10 \\
11 & 65 & 25 & 10 \\
\hline
\end{tabular}

em $50 \mathrm{ml}$ de água. Posteriormente, foram adicionados mais $75 \mathrm{ml}$ de água fervente para atingir a textura desejada de gelatinização. A mistura entre os finos de carvão vegetal, resíduo celulósico e amido foi feita manualmente sob uma lona plástica com o auxílio de uma espátula para homogeneização, o que resultou num material uniforme, com consistência que permitiu a formação dos briquetes.

A briquetagem (prensagem) do material homogeneizado foi realizada no interior de um molde metálico cilíndrico, confeccionado em aço inoxidável, utilizando-se uma prensa hidráulica com capacidade para 15 toneladas, sendo a pressão aplicada mantida durante $5 \mathrm{~min}$. Foram confeccionados 20 briquetes para cada tratamento. Terminada a briquetagem, metade dos briquetes produzidos em cada tratamento foi submetida à secagem em estufa regulada a $105 \pm 3{ }^{\circ} \mathrm{C}$ por $48 \mathrm{~h}$, sendo a outra metade submetida à secagem ao ar livre até a estabilização da umidade com o ambiente.

Após o período de secagem, os briquetes foram pesados e transferidos para uma câmara fria com condições de umidade e temperatura controladas (umidade relativa de $65 \%$ e temperatura ambiente de $20^{\circ} \mathrm{C}$ ) por cerca de 30 dias até que apresentassem peso constante e estabilizassem com a umidade de equilíbrio, a fim de que as amostras comparadas nos diferentes ensaios não possuíssem diferenças significativas de umidade e pudessem ser comparadas entre si.

\subsection{Densidades Aparentes dos Briquetes}

A densidade aparente dos briquetes foi determinada a partir da adaptação da metodologia descrita por Trugilho et al. (1990), por meio do método de imersão e variação do peso do líquido. A impermeabilização dos briquetes, necessária para a determinação de seus volumes, foi obtida a partir do envolvimento dos corpos de prova com um filme de polietileno.

\subsection{Ensaios de Resistência Mecânica}

Os ensaios de resistência à compressão foram realizados com o intuito de determinar o comportamento mecânico dos briquetes quando submetidos a determinada carga ou esforço. No teste de aplicação de carga foi utilizada uma máquina universal de ensaios, marca Contenco, modelo UMC-300, com capacidade para 30 toneladas. A célula de carga utilizada foi de 10 toneladas, em que a carga foi aplicada na parte superior dos briquetes individualmente.

\subsection{Ensaios Químicos}

A análise química imediata (teor de voláteis, teor de cinzas e carbono fixo) foi realizada em triplicata de acordo com a normaABNTNBR 8112/86. Para determinação do teor de voláteis, utilizou-se aproximadamente $1,0 \mathrm{~g}$ de amostra seca com granulometria de 60 mesh $(0,25 \mathrm{~mm})$. Cada amostra foi acondicionada em um cadinho de porcelana previamente pesado e tarado, o qual foi tampado e conduzido a uma mufla à temperatura de 950 $\pm 10^{\circ} \mathrm{C}$, em que permaneceu por $2 \mathrm{~min}$ sobre a porta aberta, por $3 \mathrm{~min}$ na borda da mufla e por $6 \mathrm{~min}$ no seu interior com a porta fechada. O teor de voláteis foi calculado pela diferença entre as massas antes e depois do aquecimento, em porcentagem.

Para a análise do teor de cinzas, pesou-se aproximadamente $1,0 \mathrm{~g}$ de material seco e com granulometria de 60 mesh $(0,25 \mathrm{~mm})$ em um cadinho

Revista Árvore, Viçosa-MG, v.40, n.1, p.173-180, 2016 
de porcelana, o qual foi levado a um forno mufla a $750 \pm 10^{\circ} \mathrm{C}$ por $6 \mathrm{~h}$. Após esse intervalo, o cadinho foi colocado e mantido em dessecador até atingir a temperatura ambiente, aferindo-se a massa final. O teor de cinzas foi determinado pelo cálculo da massa residual pós-aquecimento, em porcentagem.

Por fim, o teor de carbono fixo foi calculado subtraindo-se da totalidade (100\%) a soma dos teores de voláteis e de cinzas das amostras.

Para o cálculo do poder calorífico superior (PCS), foi utilizado um calorímetro da marca Ika Werke, modelo C5000 Control, e amostras isentas de umidade com granulometria de 60 mesh $(0,25 \mathrm{~mm})$, tendo como base a norma ABNT NBR 8633/84.

\subsection{Análises Estatísticas}

Os resultados foram avaliados e discutidos a partir da observação das médias e dos coeficientes de variação de cada tratamento. Apenas nos ensaios de análise química imediata e poder calorífico não foram considerados os diferentes procedimentos de secagem dos briquetes. Determinou-se, também, o coeficiente de correlação linear entre os resultados obtidos nos ensaios de densidade aparente e resistência a compressão.

\section{RESULTADOS}

\subsection{Densidades Aparentes dos Briquetes}

A Tabela 2 apresenta os resultados da densidade aparente e da umidade de equilíbrio dos briquetes produzidos.
Os briquetes produzidos somente com finos de carvão vegetal e resíduo celulósico $\left(\mathrm{T}_{1}-\mathrm{T}_{5}\right)$ apresentaram valor médio de densidade aparente de $0,7214 \mathrm{~g} / \mathrm{cm}^{3}$, correspondendo a aproximadamente 2,17 vezes a densidade média de diferentes espécies de carvão vegetal oriundos da madeira de eucalipto que, segundo Brito e Barrichelo (1980), é de 0,332 $\mathrm{g} / \mathrm{cm}^{3}$. Já os briquetes compactados com amido de milho $\left(\mathrm{T}_{6}-\mathrm{T}_{11}\right)$ apresentaram valores de densidade aparente maiores, com um valor médio de $0,983 \mathrm{~g} /$ $\mathrm{cm}^{3}$, o que comprovou a eficiência do processo de briquetagem em fornecer combustíveis sólidos mais densos, além de confirmar que a presença do amido de milho como aglutinante favoreceu fortemente a compactação dos resíduos.

A maior densidade aparente foi obtida com os briquetes do tratamento $\mathrm{T}_{6}(0 \%$ de resíduo celulósico e $10 \%$ de amido), e a densidade dos briquetes compactados com amido decresceu com o aumento da porcentagem de resíduo celulósico. Além disso, notou-se que a condição de secagem em estufa resultou em densidades ligeiramente maiores, em virtude da diminuição dos volumes dos briquetes, que foi ocasionada uma vez que esse tipo de secagem ocorreu de forma mais drástica e rápida, provocando o encolhimento dos corpos de prova.

As umidades de equilíbrio, nas condições ambientais em que os briquetes foram produzidos, variaram de $10,35 \%$ a $11,03 \%$. Os valores absolutos médios se mostraram próximos e não foram detectadas diferenças do ponto de vista estatístico.

Tabela 2 - Densidade aparente média $\left(\mathrm{g} / \mathrm{cm}^{3}\right)$ e umidade de equilíbrio dos briquetes produzidos.

Table 2 - Average apparent density $\left(\mathrm{g} / \mathrm{cm}^{3}\right)$ and equilibrium humidity of the produced briquettes.

\begin{tabular}{|c|c|c|c|c|}
\hline \multirow[t]{2}{*}{ Tratamento } & \multirow[t]{2}{*}{ Resíduo (\%) } & \multicolumn{2}{|c|}{ Densidade aparente } & \multirow[t]{2}{*}{ Umidade $(\%$} \\
\hline & & Estufa $^{1}$ & Ar livre ${ }^{1}$ & \\
\hline $\mathrm{T}_{1}$ & 25 & $0,716(2,45)$ & $0,682(1,98)$ & 11,35 \\
\hline $\mathrm{T}_{2}$ & 30 & $0,755(2,47)$ & $0,700(2,34)$ & 10,93 \\
\hline $\mathrm{T}_{3}^{2}$ & 35 & $0,772(4,69)$ & $0,705(3,80)$ & 10,66 \\
\hline $\mathrm{T}_{4}^{3}$ & 40 & $0,663(3,27)$ & $0,675(2,26)$ & 11,03 \\
\hline $\mathrm{T}_{5}^{4}$ & 45 & $0,776(6,21)$ & $0,770(5,99)$ & 10,87 \\
\hline $\mathrm{T}_{6}^{3}$ & 0 & $1,701(15,61)$ & $1,117(26,04)$ & 10,78 \\
\hline $\mathrm{T}_{7}^{6}$ & 5 & $1,097(7,68)$ & $0,914(7,15)$ & 10,96 \\
\hline $\mathrm{T}_{8}$ & 10 & $0,927(17,04)$ & $0,906(11,17)$ & 10,95 \\
\hline $\mathrm{T}_{9}^{8}$ & 15 & $0,926(8,36)$ & $0,903(9,98)$ & 10,89 \\
\hline $\mathrm{T}_{10}^{9}$ & 20 & $0,866(5,15)$ & $0,829(6,11)$ & 10,91 \\
\hline $\mathrm{T}_{11}^{10}$ & 25 & $0,825(21,18)$ & $0,790(7,87)$ & 10,95 \\
\hline
\end{tabular}

${ }^{1}$ Os valores entre parênteses referem-se ao coeficiente de variação.

Revista Árvore, Viçosa-MG, v.40, n.1, p.173-180, 2016 


\subsection{Ensaios de Resistência Mecânica}

A Tabela 3 apresenta os resultados obtidos da variável resistência a compressão (carga de ruptura em kgf) dos briquetes produzidos.

\subsection{Ensaios Químicos}

A Tabela 4 apresenta os resultados médios obtidos nas análises químicas imediatas dos briquetes produzidos e respectivos poderes caloríficos.

\section{DISCUSSÃO}

\subsection{Ensaios de Resistência Mecânica}

Os briquetes resultantes dos tratamentos $\mathrm{T}_{1}-\mathrm{T}_{5}$ (sem amido de milho) apresentaram baixos valores de resistência mecânica, com uma resistência máxima de
$25,80 \mathrm{kgf}$ (para $\mathrm{T}_{5}$ com secagem ao ar livre), sendo observado que, quanto maior a proporção de resíduo celulósico em sua composição, maior a resistência mecânica do briquete. Já nos tratamentos $\mathrm{T}_{6}-\mathrm{T}_{11}$, os quais apresentavam amido de milho em sua composição, foram obtidos resultados superiores de resistência a compressão. Nesse caso, quanto menor a proporção de resíduo celulósico no briquete, maior a resistência mecânica.

Observou-se também que os briquetes secos ao ar livre apresentaram maior resistência mecânica a compressão que os secos em estufa. Esse fato pode ser justificado uma vez que a secagem em estufa acontece mais rapidamente, de modo que a quantidade de água que se movimenta do interior para a superfície do briquete geralmente é menor que a quantidade de água que evapora na sua superfície. Assim, o meio da peça não acompanha

Tabela 3 - Resultados médios de resistência à compressão (kgf) dos briquetes produzidos. Table 3 - Average results for compression resistance ( $k g f)$ of the produced briquettes.

\begin{tabular}{|c|c|c|c|}
\hline \multirow[t]{2}{*}{ Tratamento } & \multirow{2}{*}{$\begin{array}{c}\text { Resíduo } \\
(\%)\end{array}$} & \multicolumn{2}{|c|}{ Processo de secagem } \\
\hline & & Estufa $^{1}$ & Ar livre ${ }^{1}$ \\
\hline $\mathrm{T}_{1}$ & 25 & $4,23(30,74)$ & $5,57(22,89)$ \\
\hline $\mathrm{T}_{2}$ & 30 & $7,67(12,87)$ & $9,53(11,70)$ \\
\hline $\mathrm{T}_{3}$ & 35 & $9,17(14,73)$ & $11,03(12,37)$ \\
\hline $\mathrm{T}_{4}$ & 40 & $11,93(8,27)$ & $12,07(15,67)$ \\
\hline $\mathrm{T}_{5}$ & 45 & $18,90(13,35)$ & $25,80(22,83)$ \\
\hline $\mathrm{T}_{6}$ & 0 & $70,8(44,90)$ & $85,40(27,59)$ \\
\hline $\mathrm{T}_{7}$ & 5 & $50,6(29,89)$ & $57,80(45,75)$ \\
\hline $\mathrm{T}_{8}$ & 10 & $22,4(28,69)$ & $39,60(57,99)$ \\
\hline $\mathrm{T}_{9}$ & 15 & $20,8(15,73)$ & $37,40(37,89)$ \\
\hline $\mathrm{T}_{10}$ & 20 & $23,4(13,38)$ & $36,40(41,14)$ \\
\hline $\mathrm{T}_{11}$ & 25 & $26,2(27,71)$ & $35,60(43,23)$ \\
\hline
\end{tabular}

${ }^{1}$ Os valores entre parênteses referem-se ao coeficiente de variação.

Tabela 4 - Análise química imediata e poder calorífico superior (PCS) a $0 \%$ de umidade $(\mathrm{kcal} / \mathrm{kg})$ dos briquetes confeccionados. Table 4-Immediate chemical analyses and gross calorific value (GCV) at $0 \%$ of moisture content (kcal/kg) of the briquettes produced.

\begin{tabular}{|c|c|c|c|c|}
\hline Tratamento & Voláteis $(\%)^{1}$ & Cinzas $(\%)^{1}$ & Carbono fixo (\%) & $\mathrm{PCS}(\mathrm{kcal} / \mathrm{kg})^{1}$ \\
\hline $\mathrm{T}_{1}$ & $27,08(14,64)$ & $28,33(18,94)$ & $44,58(13,06) \quad a b$ & $4611,23(1,88)$ \\
\hline $\mathrm{T}_{2}$ & $27,50(28,49)$ & $34,17(20,54)$ & $38,33(15,06)$ bc & $4687,76(0,54)$ \\
\hline $\mathrm{T}_{3}$ & $34,33(13,22)$ & $27,83(22,71)$ & $37,83(17,01) \quad \mathrm{c}$ & $4589,14(0,64)$ \\
\hline $\mathrm{T}_{4}$ & $26,67(11,57)$ & $26,83(14,72)$ & $46,50(8,28)$ & $4426,88(0,46)$ \\
\hline $\mathrm{T}_{5}^{4}$ & $31,00(9,33)$ & $24,33(31,80)$ & $44,67(12,35) \quad a b$ & $4241,33(0,12)$ \\
\hline $\mathrm{T}_{6}$ & $27,50(14,50)$ & $18,33(18,23)$ & $54,17(10,22) \quad$ abc & $4371,12(1,74)$ \\
\hline $\mathrm{T}_{7}^{0}$ & $33,17(13,29)$ & $30,83(16,70)$ & $36,00(8,03)$ & $4490,52(0,23)$ \\
\hline $\mathrm{T}_{8}$ & $26,67(12,21)$ & $36,25(8,57)$ & $37,08(6,94)$ & $4564,19(0,64)$ \\
\hline $\mathrm{T}_{9}$ & $36,67(15,75)$ & $23,33(16,68)$ & $40,00(14,10) \quad$ abc & $4386,88(0,98)$ \\
\hline $\mathrm{T}_{10}$ & $27,92(11,97)$ & $33,33(16,10)$ & $38,75(14,69) \quad b c$ & $4384,01(0,11)$ \\
\hline $\mathrm{T}_{10}$ & $28,33(11,49)$ & $35,00(12,18)$ & $36,67(12,10) \mathrm{c}$ & $4442,04(4,22)$ \\
\hline
\end{tabular}

${ }^{1}$ Os valores entre parênteses referem-se ao coeficiente de variação. 
a contração da camada superficial do briquete, o que acarreta pontos de tensões e possíveis rachaduras, diminuindo a sua resistência mecânica.

Segundo trabalho de Doat e Petroff (1975), é possível observar correlação de média intensidade entre a densidade aparente do carvão e a sua resistência mecânica a compressão. Nesse contexto, determinou-se a correlação entre as densidades dos briquetes confeccionados $\left(\mathrm{g} / \mathrm{cm}^{3}\right)$ e suas resistências mecânicas $\left(\mathrm{kgf} / \mathrm{cm}^{2}\right)$ (Figura 1).

A Figura 1 permitiu confirmar a existência de uma correlação de média intensidade $(R=0,7505)$ entre a densidade aparente e a carga de ruptura dos briquetes, comprovando que, quanto maior a compactação obtida no processo de briquetagem, maior a resistência mecânica alcançada pelos corpos de prova. Notou-se que os briquetes contendo amido de milho tiveram densidades aparentes superiores, o que consequentemente ocasionou briquetes mais resistentes e estáveis. Esse fato confirmou a necessidade da utilização do amido de milho como aglutinante para a confecção desses briquetes, sendo os tratamentos $\mathrm{T}_{7}$ e $\mathrm{T}_{8}$, que exibiram menores quantidades de resíduo celulósico (5 e 10\%, respectivamente), os que forneceram os briquetes mais resistentes na condição de secagem ao ar livre.

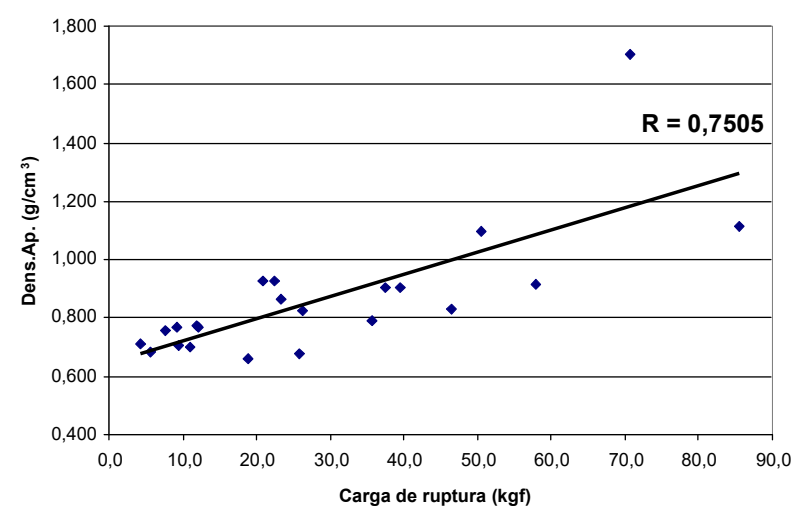

Figura 1 - Gráfico da correlação entre a densidade aparente e a carga de ruptura encontrada no ensaio de resistência à compressão dos briquetes $(\mathrm{R}=$ coeficiente de correlação)

Figure 1-Graph of apparent density and rupture load correlation found in the test of resistance to compression of the briquettes $(R=$ correlation coefficient $)$.

\subsection{Ensaios Químicos}

Segundo Juvillar (1980), o carvão vegetal (base seca) apresenta composição química média de $25 \%$ de teor de material volátil, $5 \%$ de teor de cinzas e $70 \%$ de teor de carbono fixo. Observou-se que os briquetes confeccionados tiveram média de teor de voláteis próxima à do valor esperado $(29,71 \%)$ para o carvão vegetal puro, indicando que a adição de resíduo celulósico pouco afetou o teor de material volátil presente nas amostras.

Em contrapartida, a média de teor de cinzas dos briquetes confeccionados foi muito superior à do valor estimado $(28,96 \%)$. Esse alto valor encontrado nas amostras para o teor de cinzas pode ser explicado pela possível presença, no resíduo celulósico, de cargas (caulim, carbonato de cálcio, dióxido de titânio e silicato hidratado de magnésio), geralmente utilizadas para alterar a alvura, a lisura, a opacidade e a gramatura do papel, além do uso de aditivos (colas, revestimentos, coligantes, dispersantes, antiespumantes, agentes preservativos, entre outros), que são utilizados para alterar as propriedades físicas, químicas, mecânicas e ópticas do papel (PINHEIRO et al., 2008; ALMEIDA et al., 2007; VELÁZQUEZ, 2000).

Em virtude do alto teor de cinzas, observou-se menor teor de carbono fixo nos briquetes confeccionados, o que afeta negativamente seu desempenho energético, ocasionando queima mais rápida desse combustível. Tanto o teor de carbono fixo quanto o poder calorífico dependem da quantidade de material orgânico presente no briquete (OBERNBERGER; THEK, 2004). Nos tratamentos $\mathrm{T}_{1}-\mathrm{T}_{3}(25 \%, 30 \%$ e $35 \%$ de teor de resíduo celulósico) não houve diferença significativa em relação ao poder calorífico. No entanto, os valores de poder calorífico para os tratamentos $\mathrm{T}_{4}$ e $\mathrm{T}_{5}$, os quais apresentavam maiores quantidades de resíduo celulósico ( $40 \%$ e $45 \%$, respectivamente), foram significativamente inferiores aos demais.

Já nos briquetes compactados com amido de milho o poder calorífico teve ligeira diminuição em relação aos briquetes compactados somente com resíduo celulósico, embora entre os tratamentos $T_{6}-T_{11}$ não seja observada diferença significativa entre eles quanto aos valores de poder calorífico. Esse fato confirmou novamente que em pequenas proporções (0-35\%) a presença do resíduo celulósico não afetou, de maneira significativa, o poder calorífico dos briquetes. 


\section{CONCLUSÕES}

De acordo com os resultados, pode-se concluir que os briquetes produzidos com finos de carvão vegetal e resíduo celulósico se mostraram fonte viável para a geração de energia e o aproveitamento desse material, que são subprodutos do mercado de carvão vegetal e da indústria de papel e celulose. Observou-se que foi imprescindível a adição de amido de milho como aglutinante para obtenção de briquetes de maior densidade e resistência mecânica, o que indicou que a retirada total do amido de milho na composição dos briquetes foi prejudicial à sua estabilidade e durabilidade.

Observou-se também que o processo de secagem em estufa, de maneira geral, prejudicou a qualidade dos briquetes, de modo que a secagem ao ar livre, embora seja mais demorada, resultou em briquetes de maior resistência mecânica, o que facilita o seu manuseio e transporte. Assim, concluiu-se que os tratamentos realizados com pequenas proporções de resíduo celulósico (5-10\%), utilizando amido de milho como aglutinante e com secagem ao ar livre, resultaram nos briquetes de melhor qualidade.

Quanto à análise química, observou-se que os tratamentos de modo geral apresentaram alto teor de cinzas, resultando em menor teor de carbono fixo quando comparado com briquetes de carvão vegetal. Embora esse fato prejudique o desempenho energético dos briquetes, o alto teor de cinzas sugere que esses briquetes são ricos em minerais e podem, eventualmente, ser utilizados como adubo mineral na agricultura.

\section{REFERÊNCIAS}

ALMEIDA, H.C.; SILVEIRA, C.B.; ERNANI, P.R.; CAMPOS, M.L.; ALMEIDA, D. Composição química de um resíduo alcalino da indústria de papel e celulose (DREGS). Química Nova, v.30, n.7, p.1669-1672, 2007.

ANDRADE, G.C.; SILVA, H.D.; BELLOTE, A.F.J.; FERREIRA, C.A. Efeitos da adubação fosfatada e da aplicação de resíduo de celulose no crescimento de Eucalyptus dunnii. Boletim de Pesquisa Florestal, v.47, p.43-54, 2003.

\section{ASSOCIAÇÃO BRASILEIRA DE NORMAS} TÉCNICAS - ABNT. NBR 8633/84. Carvão vegetal - Determinação do poder calorífico. São Paulo: 1984.
ASSOCIAÇÃO BRASILEIRA DE NORMAS TÉCNICAS - ABNT. NBR 8112/86. Carvão vegetal - Análise imediata. São Paulo: 1986.

BAILIS, R.; RUJANAVECH, C.; DWIVEDI, P.; VILELA, A.O.; CHANG, H.; MIRANDA, R.C. Innovation in charcoal production: A comparative life-cycle assessment of two kiln technologies in Brazil. Energy for Sustainable Development, v. 17, p.189-200, 2013.

BRITO, J.O.; BARRICHELO, L.E. Correlações entre características físicas e químicas da madeira e a produção de carvão: densidade da madeira $x$ densidade do carvão. Piracicaba: IPEF, 1980. p.101-113.

DERMIBAS, A. Properties of charcoal derived from hazelnut shell and the production of briquettes using pyrolytic oil. Energy, v.24, p.141-150, 1999.

DOAT, J.; PETROFF, G. La carbonization des bois tropicaux. Bois et Forêts des Tropiques, v.159, p.55-72, 1975.

FONTES, P.J.P.; QUIRINO, W.F.; PASTORE, J.R.F.; FILGUEIRAS, S.M.S. Aglutinante para briquetagem de carvão vegetal. Brasília: Laboratório de Produtos Florestais, Departamento de Pesquisas, Instituto Brasileiro de

Desenvolvimento Florestal, 1984. p.1-5.

FONTES, P.J.; QUIRINO, W.F.; OKINO, E.Y. Aspectos técnicos da briquetagem de carvão vegetal no Brasil. Brasília: Laboratório de Produtos Florestais, Departamento de Pesquisas, Instituto Brasileiro de Desenvolvimento Florestal, 1989. p.1-14.

HARRISON, R.B.; GUERRINI, I.A.; HENRY, C.L.; COLE, D.W. Reciclagem de resíduos industriais e urbanos em áreas de reflorestamento. Circular Técnica IPEF, n.198, p.1-20, 2003

JUVILlaR, J.B. Tecnologias de transformação de madeira em carvão. Belo Horizonte: Fundação Centro Tecnológico de Minas Gerais/CETEC - Série de Publicações Técnicas / SPT -1980.

MACHADO, J.G.M.S.; OSÓRIO, E.; VILELA, A.C.F. Reactivity of brazilian coal, charcoal,

Revista Árvore, Viçosa-MG, v.40, n.1, p.173-180, 2016 
imported coal and blends aiming to their injection into blast furnaces. Material Research, v.13, n.3, p.287-292, 2010.

OBERNBERGER, I.; THEK, G. Physical chatacterisation and chemical composition of densified biomass fuels with regard to their combustion behavior. Biomass end Bioenergy, v.27, n.6, p.653-669, 2004.

ONAJI, P.B.; SIEMONS, R.V. Production of charcoal briquettes from cotton stalks in Malawi: Methodology for feasibility studies using experiences in Sudan. Biomass and Bioenergy, v.4, p.199-211, 1993.

PEREIRA, F.A.; CARNEIRO, A.C.O.; VITAL, B.R.; DELLA LUCIA, R.M.; PATRICIO JÚNIOR, W.; BIANCHE, J.J. Propriedades físico-químicas de briquetes aglutinados com adesivo de silicato de sódio. Floresta e Ambiente, v.16, n.1, p.23$29,2009$.

PINHEIRO, R.M.I.; VIEIRA, C.M.F.I.; RODRIGUEZ, R.S.I.; MONTEIRO, S.N.I.

Reciclagem de resíduo proveniente da produção de papel em cerâmica vermelha. Revista Matéria, v.13, n.1, p.220-227, 2008.
RODRIGUES, C.M.; BELLOTE, A.F.J.; DEDECEK, R.A.; GOMES, F.S. Alterações na nutrição e na produtividade do Pinus taeda L. provocadas pela aplicação de resíduo celulósico. Boletim de Pesquisa Florestal, v.51, p.131-143, 2005.

ROUSSET, P.; PIRES, A.C.; SABLOWSKI, A.; RODRIGUES, T. LCA of eucalyptus wood charcoal briquettes. Journal of Cleaner Production, v.19, p.1647-1653, 2011.

SAMI, M.; ANNAMALAI, K.; WOOLDRIDGE, M. Co-firing of coal and biomass fuel blends.

Progress Energy Combustion Science, v.27, p.171-214, 2001.

TRUGILHO, P.F.; SILVA, D.A.; FRAZÃO, F.J.L.; MATOS, J.L.M. Comparação de métodos de determinação de densidade básica em madeiras. Acta Amazônica, v.20, (único): p.307-319, 1990.

VELÁZQUEZ, S.M.S.G. A cogeração de energia no segmento de papel e celulose: Contribuição à matriz energética do Brasil. 2000. 191f. Tese (Mestrado em Energia) - Setor de Energia da Universidade de São Paulo, USP, São Paulo, 2000. 